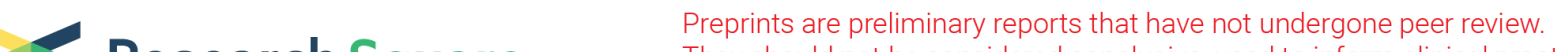 Research Square They should not be considered conclusive, used to inform clinical practice, or referenced by the media as validated information.
}

\section{Mechanical /thermal Shock Properties and Failure Mechanisms of Cf/SiBCN Composites Effect of Sintering Densification and Fiber Coating}

Zi-bo Niu (D 1817828519@qq.com )

Harbin Institute of Technology

BingZu Wang

Harbin Institute of Technology

Lijun Pan

Harbin Institute of Technology

Daxin Li

Harbin Institute of Technology

Dechang Jia

Harbin Institute of Technology

Zhihua Yang

Harbin Institute of Technology

Hao Peng

Harbin Institute of Technology

Yu Zhou

Harbin Institute of Technology

\section{Research Article}

Keywords: $\mathrm{Cf} / \mathrm{SiBCN}$ composites, fiber coating, sintering temperature, mechanical properties, thermal shock properties

Posted Date: November 5th, 2021

DOI: https://doi.org/10.21203/rs.3.rs-1023611/v1

License: (c) (i) This work is licensed under a Creative Commons Attribution 4.0 International License.

Read Full License 


\section{Abstract}

In this work, resin derived carbon coating was prepared on carbon fibers by polymer impregnation pyrolysis method (PIP), and then $\mathrm{C}_{f} / \mathrm{SiBCN}$ composites were prepared by hot pressing process. The effects of sintering densification and fiber coating on microstructure, mechanical properties, thermal shock resistance, and failure mechanisms of the composites were studied. Fiber bridging hinders the sintering densification, causing more defects in fiber-dense area and lower strength. However, higher sintering temperature $\left(1800-2000^{\circ} \mathrm{C}\right)$ can improve mechanical properties significantly, including bending strength, vickers hardness, and elastic module, because further sintering densification enhances matrix strength and fiber/matrix bonding strength, while the change of fracture toughness is not obvious (2.242.38 MPa $\mathrm{m}^{1 / 2}$ ) due to counteraction of higher debonding resistance and less pull-out length. However, fiber coating improves fracture toughness greatly via protecting carbon fibers from chemical corrosion and damage of thermal stress and external stress. Due to lower coefficient of thermal expansion, lower fiber loading ratio, less stress concentration at the fiber/matrix interface and better defect healing effect, lower sintering temperature favor thermal shock resistance of composites and thermal shock recession mechanisms are the damage of interface.

\section{Introduction}

Traditional silicon-based ceramics and their composites such as $\mathrm{SiO}_{2}, \mathrm{SiC}, \mathrm{Si}_{3} \mathrm{~N}_{4}$ and their composites have excellent properties such as low density, high specific strength, and high chemical stability, which are widely used in various high temperature structural components, such as high temperature engines, turbines, catalyst heat exchangers, combustion systems, high temperature sensors, etc [1-4]. However, when the service temperature is higher than $1500^{\circ} \mathrm{C}$, their strength and oxidation resistance will decrease sharply. For example, above $1300^{\circ} \mathrm{C}$, the precipitation of cristobalite and high-temperature creep will cause strength degradation of $\mathrm{SiO}_{2}$. Above $1400{ }^{\circ} \mathrm{C}, \mathrm{Si}_{3} \mathrm{~N}_{4}$ undergoes severe thermal decomposition and above $1600^{\circ} \mathrm{C}, \mathrm{SiC}$ is significantly oxidized due to softening of protective $\mathrm{SiO}_{2}$ oxide film [5]. Therefore, the traditional silicon-based ceramics and their composites cannot meet the requirements of long-term service above $1600^{\circ} \mathrm{C}[6]$.

Silicon-boron-carbon-nitrogen (SiBCN) system metastable ceramics is a new type of high temperature structural-functional ceramic, which have long-range disordered and short-range ordered amorphous state at low temperature, and nanocapsule-like structure characteristics at high temperature [7-8]. Due to its unique microstructure, $\mathrm{SiBCN}$ ceramics have more excellent performance characteristics at high temperature than traditional silicon-based ceramics, such as lowest oxidation coefficient among nonoxide ceramics, lower thermal expansion coefficient, and excellent high temperature mechanical properties, and can even meet the service requirements at high temperature of $2000{ }^{\circ} \mathrm{C}$ [8-9]. At present, the $\mathrm{SiBCN}$ ceramics are mainly derived by pyrolysis of precursor (PDCs) or prepared by inorganic method. Despite the excellent performance of PDCs-SiBCN, its commercial utility is limited by the shortcomings of expensive raw materials, low-yield, complex preparation process, hard control of volume shrinkage to 
avoid defect, and harmful to human health and the environment [7]. Using inorganic powders (such as Si, $\mathrm{C}, \mathrm{B}, \mathrm{BN}$, etc.) instead of organic precursor as raw materials, the inorganic method based on mechanical alloying (MA), coupled with subsequent sintering process avoids these disadvantages and develops as a simple and effective way to prepare MA-SiBCN monoliths with the uniform microstructures and superior properties [7].

However, like most ceramics, the brittleness and poor reliability of SiBCN ceramics hinder its practical application. The toughness can be improved by adding reinforcements such as fibers, whiskers, particles, graphenes and carbon nanotubes [10-14]. Among them, the carbon fiber toughening effect is the most significant: through fiber debonding, fracture and pull-out, composites show pseudo-plasticity rather than brittle fracture, and their mechanical properties are not sensitive to micro-defects, which greatly improves damage tolerance and service reliability [10].

At present, $\mathrm{C}_{\mathrm{f}} / \mathrm{SiBCN}$ composites are mainly prepared via densifying carbon fiber preform through repeated precursor infiltration pyrolysis (PIP) [10,15-16]. However, precursor preparation involves high requirements and cost and repeated PIP process (up to 12 times) requires long preparation cycle [16]. Hot pressing method has low cost of raw material (MA-SiBCN powder) and short process cycle (about 30h) and is easy to realize mass production. However, there are few studies on the preparation and properties of $\mathrm{C}_{f} / \mathrm{SiBCN}$ composites by hot pressing.

The protection of fibers and the densification of matrix are the main problems faced by hot pressing method. During hot pressing process, high temperature and pressure lead to fiber damage and degradation of mechanical properties. In addition, due to poor sintering performance of SiBCN powder and fiber agglomeration, densification of $\mathrm{C}_{f} / \mathrm{SiBCN}$ composites requires higher sintering temperatures than traditional ceramics. In this study, resin-derived carbon was coated on the surface of carbon fibers by PIP process, playing the role of interface phase, such as reduction of the physical and chemical damage to fibers in the preparation process and formation of the moderate fiber/matrix interface bonding. Then, the dispersed fibers were mixed with SiBCN powder and pressed in mold at different sintering temperatures $\left(1800-2000^{\circ} \mathrm{C}\right)$ to prepare different $\mathrm{C}_{f} / \mathrm{SiBCN}$ composites. The effects of fiber coating and sintering densification on the microstructure, mechanical properties at room temperature and thermal shock resistance of the composites were studied, and the failure mechanisms and thermal shock recession mechanisms of the different composites were explored.

\section{Experimental Method}

\subsection{Material Preparation}

Preparation process of $\mathrm{C}_{f} / \mathrm{SiBCN}$ composites is shown in Fig. 1, including preparation of amorphous SiBCN powder by mechanical alloying, preparation of fiber coating by PIP process and preparation of $\mathrm{C}_{\mathrm{f}} / \mathrm{SiBCN}$ composites by hot pressing. 


\subsubsection{Preparation of amorphous SiBCN powder}

Amorphous SiBCN powders were prepared from cubic silicon powder with an average particle size of $15.5 \mu \mathrm{m}$ (Beijing Mengtai Research and Development Center Co., Ltd., Beijing), h-BN powder with an average particle size of $0.6 \mu \mathrm{m}$ (Fangyuan Boron Nitride Factory Co., Ltd., China) and graphite powder (Qingdao Huatai Lubrication and Sealing Technology Co., Ltd., China) by high-energy ball milling. The chemical composition of amorphous SiBCN powders was designed as Si:B:C:N = 2:1:3:1 and the detail preparation parameters were described in [17]. The SiBCN powder has uniform particle size of about 200nm (see Fig. 2(a)), and high non-crystallization degree ( see the XRD pattern in Fig. 2(b)).

\subsubsection{Preparation of fiber coating}

Degummed short-cut fibers (T300, $1 \mathrm{k}$, Toray) with length of $1-2 \mathrm{~mm}$ were immersed in $40 \mathrm{~g} / \mathrm{L}$ acetone solution of phenolic resin, ultrasonically dispersed for $30 \mathrm{~min}$, dried at $100{ }^{\circ} \mathrm{C}$, cross-linked at $200{ }^{\circ} \mathrm{C}$, and pyrolyzed at $700^{\circ} \mathrm{C}$ to prepare resin-derived carbon (RCD) coating on the carbon fibers. The tensile strength and elastic modulus of the fibers are about $3000 \mathrm{MPa}$ and $210 \mathrm{GPa}$, respectively.

\subsubsection{Preparation of $\mathrm{C}_{\mathrm{f}} / \mathrm{SiBCN}$ composites by hot pressing}

After the coated carbon fibers and SiBCN powders were mixed at a volume ratio of 15:85, T1800, T1900 and T2000 composites were prepared by hot pressing at different sintering temperatures $\left(1800^{\circ} \mathrm{C}\right.$, $1900^{\circ} \mathrm{C}$ and $2000^{\circ} \mathrm{C}$ ). The sintering pressure was $60 \mathrm{MPa}$ and the sintering atmosphere was nitrogen with gas pressure of $1.0 \times 10^{5} \mathrm{~Pa}$.

\subsection{Test and characterization}

\subsubsection{Characterization}

Fiber morphology before and after coating preparation and surface and fracture morphology of composite before and after thermal shock were characterized by thermal field emission scanning electron microscope (FESEM, Quanta 200 FEG, FEI, USA) and Energy dispersive X-ray spectrum (EDS) was recorded to identify the element species in different phases. The phase composition of composites was analyzed by X-ray diffractometer (XRD, D/max- $\gamma B$, Japanese Science) with the scanning speed of $4^{\circ} / \mathrm{min}$, the accelerating voltage of $40 \mathrm{kV}$ and the current of $50 \mathrm{~mA}$. The microscopic structure and crystal structure of composites were analyzed by transmission electron microscope (TEM, PhilipsCM-12, Holland) with the accelerated voltage of $120 \mathrm{kV}$. The linear expansion coefficient of the samples of composites with the size of $3 \times 4 \times 20 \mathrm{~mm}^{3}$ was tested on thermal expansion tester (NETZSCH DIL 402C) in argon atmosphere, with increasing temperature from room temperature (RT) to $1200^{\circ} \mathrm{C}$ at $5^{\circ} \mathrm{C} / \mathrm{min}$. TGDTA of phenolic resin powder in argon atmosphere $\left(\mathrm{RT}-1400^{\circ} \mathrm{C}\right)$ and sample of composites $\left(0.5 \times 0.5 \times 0.5 \mathrm{~mm}^{3}\right)$ in air atmosphere $\left(\mathrm{RT}-1000^{\circ} \mathrm{C}\right)$ was tested by comprehensive thermal analyzer (STA449C/6/G, Niche, Germany), with heating rate of $10^{\circ} \mathrm{C} / \mathrm{min}$. The density and open porosity of the composites were determined by the water-immersion technique using the Archimedes drainage method. 


\subsubsection{Mechanical tests}

Vickers hardness of the composites was measured by HBV-30A hardness tester with load of $19.6 \mathrm{~N}$ and holding time of $5 \mathrm{~s}$. Bending strength and elastic modulus of the composites were measured by threepoint bending method on Instron-5500 universal testing machine with head movement rate of $0.5 \mathrm{~mm} / \mathrm{min}$. The sample size is $3 \times 4 \times 26 \mathrm{~mm}^{3}$ and span is $20 \mathrm{~mm}$. Fracture toughness of the composites was measured by single edge notched beam method (SENB) on Instron-1186 universal testing machine with head movement rate of $0.05 \mathrm{~mm} / \mathrm{min}$. The sample size is $2 \times 4 \times 20 \mathrm{~mm}^{3}$, span is $16 \mathrm{~mm}$, incision depth is $2 \mathrm{~mm}$, and incision width is about $0.2 \mathrm{~mm}$. At least three samples were used in each mechanical test.

\subsubsection{Thermal shock test}

After furnace was heated to the given temperature $\left(700^{\circ} \mathrm{C}, 900^{\circ} \mathrm{C}\right.$ and $\left.1100^{\circ} \mathrm{C}\right)$, the samples for the bending strength test in the crucible were directly pushed into the furnace, placed in the air atmosphere for $5 \mathrm{~min}$, quickly taken out and put into boiling water $\left(100^{\circ} \mathrm{C}\right)$.

\section{Result And Discussion}

\subsection{Microstructure of coated fiber and different composites}

Figure 3 shows the thermogravimetric (TG), differential thermogravimetric (DTG), and differential thermal analysis (DTA) curves of phenolic resin pyrolysis at RT- $1000{ }^{\circ} \mathrm{C}$. Carbon residue rate of the resin is about $38.8 \%$, weight loss mainly occurs at $300-600{ }^{\circ} \mathrm{C}$, and the weight loss at $350-400^{\circ} \mathrm{C}$ is the fastest (see DTG curve). The characteristic peaks of the DTA curve correspond to those of the DTG curve, indicating that obvious chemical reactions occur at specific temperatures. According to the trend of TG curve, the pyrolysis process can be divided into three temperature sections: in low temperature section $\left(\mathrm{RT}-300^{\circ} \mathrm{C}\right)$, total weight loss rate is about $6.69 \%$. According to the DTG curve, following zero weight loss rate at 0 $100^{\circ} \mathrm{C}$, the weight loss rate reach peak $\left(14.4 \cdot 10^{-4} /{ }^{\circ} \mathrm{C}\right)$ at $100-150^{\circ} \mathrm{C}$ corresponding to the endothermic peak of DTA, due to the endothermic process of moisture evaporation, and then the weight loss rate maintain at about $5 \cdot 10^{-4} /{ }^{\circ} \mathrm{C}\left(150-300^{\circ} \mathrm{C}\right)$, due to dehydration of the active hydrogen and hydroxymethyl groups during curing [18]. In medium temperature region $\left(300-600^{\circ} \mathrm{C}\right)$, resin has the most weight loss of $38.8 \%$. At $450-600^{\circ} \mathrm{C}$, weight decreases linearly at the rate of about $9 \cdot 10^{-4} /{ }^{\circ} \mathrm{C}$ with increasing temperature, while there is an obvious peak of weight loss rate at $300-450^{\circ} \mathrm{C}\left(44 \cdot 10^{-4} /{ }^{\circ} \mathrm{C}\right)$. In this temperature region, due to the violent thermal polycondensation and decomposition reactions, polymer chain gradually transforms into graphite crystallite structure [18] and the peak at $350-400^{\circ} \mathrm{C}$ corresponds to decomposition of main chain. In high temperature region $\left(600-1000^{\circ} \mathrm{C}\right)$, the weight loss is about $5 \%$. The weight loss rate gradually decreases and tends to zero, with the weight loss reaching saturation $(61.15 \%)$. The weight loss at this stage is due to the dehydrogenation of aromatic hydrocarbon [18]. 
Figure 4(a-b) and (c-d) show the surface morphology of degummed carbon fibers and carbon fibers coated with resin derived carbon, respectively. Many longitudinal grooves are exposed on the surface of carbon fibers after degumming. After preparation of fiber coating, a layer of dense and uniform resinderived carbon coating is formed on the surface of carbon fibers, covering the grooves. The coating is well bonded to carbon fibers, with coating peeling and shedding only in very few areas. Fibers are well dispersed indicating that preparation of coating does not result in severe agglomeration between fibers.

With increasing sintering temperature from $1800^{\circ} \mathrm{C}$ to $1900^{\circ} \mathrm{C}$, density of the composites increases significantly. The density of T1800 is only $1.92 \mathrm{~g} / \mathrm{cm}^{3}$, whereas the density of T1900 and T2000 increases to $2.14 \mathrm{~g} / \mathrm{cm}^{3}$ and $2.18 \mathrm{~g} / \mathrm{cm}^{3}$, respectively, because the initial sintering temperature of SiBCN powder is about $1830^{\circ} \mathrm{C}$. Only when the temperature is higher than about $1830^{\circ} \mathrm{C}$, can particle rearrangement, high temperature creep and various diffusion mechanisms overcome the activation energy to function, causing obvious sintering between SiBCN particles. The theoretical density of amorphous SiBCN is generally considered as $2.83 \mathrm{~g} / \mathrm{cm}^{3}$, so relative density of T1800, T1900 and T2000 composites can be calculated as $71 \%, 81 \%$ and $83 \%$, respectively. With the same sintering processes, the relative density of SiBCN monolithic sintered at 1800,1900 and $2000^{\circ} \mathrm{C}$ can reach about $74 \%, 88 \%$ and $93 \%$, respectively [19]. Obviously, the addition of fibers obviously hinders the sintering densification, mainly due to bridging between fibers. The fiber bridging hinders the flow and rearrangement of particles and increases the diffusion distance, causing sintering mechanisms not to fully function. Therefore, defects such as pores and cracks tend to leave in fiber-dense area (see Fig. 5).

Figure 4(a-c) shows surface morphology of T1800, T1900 and T2000 composites parallel to pressing direction (vertical plane). Most of fibers are distributed in plane perpendicular to the pressing direction (horizontal plane), because during the hot pressing process, SiBCN powder drives fibers to flow, causing preferential distribution of fibers in the plane perpendicular to the pressure direction. In fiber dense area, different degrees of matrix shedding occurs, exposing the fiber end, because fiber bridging in the fiberdense area causes difficulty of sintering densification and decrease of matrix strength. Besides, the axial thermal expansion coefficient of carbon fiber $\left(-0.7 \cdot 10^{-6}\right)$ is much lower than the thermal expansion coefficient of the matrix $\left(3-4 \cdot 10^{-6}\right)[19]$. Due to the serious thermal expansion mismatch, thermal stress between the fibers and the matrix exceeds the tensile strength of the matrix, resulting in a large number of micro-cracks in the matrix and promoting the shedding of the matrix. With the increase of sintering temperature, the area of matrix shedding decreases gradually and only a small amount of matrix shedding occurs on the surface of T2000 composites (see in Fig. 5(c)), because further sintering densification enhances matrix strength and the fiber/matrix bonding strength. The illustration in the upper right corner of Fig. 5(a-c) is the surface morphology parallel to horizontal plane. Due to less fiber bridging in the horizontal plane, the surface is more flat and has less matrix shedding than that of vertical plane. With increasing sintering temperature, matrix shedding in horizontal plane also further decreases and there is almost no matrix shedding on the surface of T2000 composites, which further confirm the above analysis. 
According to the XDR pattern of the composites in Fig. 6(b), the SiBCN matrix of the composites is obviously crystallized, and the precipitated phases include $\mathrm{BN}(\mathrm{C}), \mathrm{a}-\mathrm{SiC}$ and $\beta-\mathrm{SiC}$ phase. $\beta-\mathrm{SiC}$ phase is main precipitated phases, and $a-S i C$ is relatively less. With increasing sintering temperature, the diffraction peaks of $\beta$-SiC and $\mathrm{a}-\mathrm{SiC}$ phases gradually become stronger and the half width at halfmaximum (FWHM) significantly narrows down, indicating improvement of crystallization degree of SiC phase. The BN(C) phase in T1800 and T1900 composites has only a weak broad peak indicating limited crystallization degree, whereas the diffraction peak of $\mathrm{BN}(\mathrm{C})$ phase in T2000 composite is significantly intensified, indicating that $\mathrm{BN}(\mathrm{C})$ phase is obviously graphitized at $2000^{\circ} \mathrm{C}$. Fig. $6(\mathrm{a})$ shows the microstructure of SiBCN matrix in T1900 composite observed by TEM. SiC nanocrystals are uniformly distributed in matrix, with mean grain size of about $30-50 \mathrm{~nm}$, but a small number of SiC grains abnormally grown with grain sizes of about 100nm. According to the microstructure (see Fig. 5(a)) and electron diffraction pattern (see Fig. 5(b)) of the SiC grains in matrix, although SiC nanocrystals have high crystallization degree, there are high-density dislocations and twins in SiC nanocrystals. The BN(C) phase is mostly distributed in the edge of the SiC grain (see Fig. 5(a)). Due to low texture, its turbulent layer structure is not clear, which is consistent with the XRD analysis results. The segregation regions of $\mathrm{Si}$ and $\mathrm{C}$ atom in the amorphous matrix may become the crystal nucleus of $\mathrm{SiC}$ phase. With increase of temperature strengthening the thermal vibration of atoms, driven by the chemical potential, the smaller atoms of $\mathrm{B}$ and $\mathrm{N}$ can overcome activation energy and diffuse out from the segregation regions of $\mathrm{Si}$ and $\mathrm{C}$ forming the segregation regions of $\mathrm{B}$ and $\mathrm{N}$ around the $\mathrm{SiC}$ crystal nucleus. With the growth of $\mathrm{SiC}$ grains, the turbulent layer $\mathrm{BN}(\mathrm{C})$ phase is formed around the $\mathrm{SiC}$ grains.

\subsection{Effect of sintering temperature on mechanical properties of composites}

Figure 7(a) shows the bending stress-displacement curve of the composites. For T1900 and T2000 composites, fracture process presents pseudoplastic behavior: after elastic linear deformation, there are jagged stress steps similar to metal yield, due to the gradual pull-out and fracture of fiber bundles. For T1800 composite, fracture process has no obvious linear elastic deformation and yield point, showing typical plastic deformation behavior. The smooth curve without jagged platform indicates that too weak interface bonding leads to little resistance of fiber debonding during fracture. With increasing sintering temperature $\left(1800-2000^{\circ} \mathrm{C}\right)$, the bending strength of the composites is significantly improved (30.4-70.5 $\mathrm{MPa})$, but the deformation amount is gradually reduced (0.22-0.075). The main reason is that higher sintering temperature activates more sintering mechanisms to significantly reduce defects and improve matrix strength. Besides, with sintering temperature increasing $\left(1800-2000^{\circ} \mathrm{C}\right)$, fiber coating has a certain degree of chemical bonding with matrix, causing higher interfacial bonding strength. Due to higher elastic modulus of carbon fiber (210 GPa) than that of SiBCN matrix (150 GPa) [19], carbon fibers are loaded prior to the matrix, so stronger interfacial bonding is conducive to more loading of the fiber. Compared with $\mathrm{SiBCN}$ monolithic prepared by the same hot pressing process, the bending strength of $\mathrm{C}_{f} / \mathrm{SiBCN}$ composites is relatively lower, because fiber bridging, poor sintering property and thermal stress release lead to a large number of defects such as micro-cracks and pores in the composites. However, due to the 
addition of carbon fibers, the composites are not sensitive to the defects and present pseudoplastic behavior during fracture failure.

Figure 8(b-d) shows the fracture morphology of T1800, T1900 and T2000 composites, respectively. The fracture surface of composites is uneven, indicating that cracks have obvious deflection near fiber bundles. The large number of pulled out fibers and the residual pits indicate that debonding and pulling out are main toughening mechanisms after fiber fracture. As sintering temperature increases, fiber pullout length gradually decreases due to increase of interfacial bonding strength. Specifically, stress concentration at interface cannot be alleviated by fiber debonding and at fiber ends, stress quickly reaches the fiber strength, resulting in a closer fracture position to the fiber end and shorter fiber pull-out length. Figure 8(a) shows fracture morphology of $\mathrm{C}_{f} / \mathrm{SiBCN}$ composite without fiber coating prepared by hot pressing at $1800^{\circ} \mathrm{C}$. Carbon fiber morphology becomes blurred with obvious distortion, indicating that even at lower sintering temperature $\left(1800^{\circ} \mathrm{C}\right)$ fibers without coating have severe physical damage and chemical corrosion. Compared with T1800 composite, pull-out length of carbon fibers is shorter and many matrix particles are adhered on the surface, showing the characteristics of brittle fracture, because the chemical bonding between carbon fibers and matrix causes too strong interfacial bonding. The fractured fibers of T1800, T1900 and T2000 composites retains the original morphology without signs of corrosion and deformation damage indicating that fiber coating has good physical and chemical compatibility with matrix and protects carbon fibers from matrix corrosion and damage of thermal stress and external stress.

Figure 7(b) shows changes of bending strength, vickers hardness, elastic modulus and fracture toughness of $\mathrm{C}_{\mathrm{f}} / \mathrm{SiBCN}$ composites with sintering temperature. With sintering temperature increasing $\left(1800-2000^{\circ} \mathrm{C}\right)$, comprehensive mechanical properties of composites are significantly improved: bending strength increases from $30.4 \mathrm{MPa}$ to $70.5 \mathrm{MPa}$, vickers hardness increases from $0.91 \mathrm{GPa}$ to $2.25 \mathrm{GPa}$, and modulus increases from $20.3 \mathrm{GPa}$ to $41.6 \mathrm{GPa}$, while the change of fracture toughness is not obvious (2.24-2.38 MPa $\mathrm{m}^{1 / 2}$ ). The improvement of vickers hardness and elastic modulus is mainly due to reduction of defects in the matrix, and the little effect of sintering temperature on the fracture toughness is caused by offset effect of two factors. On the one hand, increase of sintering temperature leads to higher matrix strength and stronger interface bonding, so greater external stress is needed for debonding and pull-out of fibers and fracture of matrix, resulting in the improvement of fracture toughness. On the other hand, with sintering temperature increasing, stronger interfacial bonding decreases the number and length of fiber pull-out, resulting in decrease of fracture toughness. Compared with sintering temperature, fiber coating has a more significant effect on fracture toughness of composites. Fracture toughness of the $\mathrm{C}_{f} / \mathrm{SiBCN}$ composites without fiber coating is only about 1.47 $\mathrm{MPa} \cdot \mathrm{m}^{1 / 2}$, indicating that fiber coating can effectively improve the toughening effect of fibers. According to its fracture morphology in Fig. 8(a), due to the serious damage of fibers and less pull-out of fibers, energy consumption of fiber fracture, debonding and pull-out is less, causing less fracture toughness.

\subsection{The oxidation and thermal expansion properties of the composites}


The thermal shock resistance of composites is determined by the oxidation resistance, mechanical properties and thermo-physical properties of composites. Therefore, the oxidation and thermal expansion properties were investigated to lay a foundation for the study on their thermal shock properties. Fig. 9(a) shows thermogravimetric curves of the composites during non-isothermal oxidation with temperature increasing from RT to $1400^{\circ} \mathrm{C}$. The curves of all composite have the similar variation trend and according to the trend of the curves, oxidation process can be divided into three stages. In low temperature section $\left(\mathrm{RT}-620^{\circ} \mathrm{C}\right)$, water volatilization and gas desorption cause obvious weight loss $(5 \%)$ at $180-260^{\circ} \mathrm{C}$ and apart from that, weight remain constant, because carbon fibers and matrix remain chemical inertia to oxygen due to the low temperature.

In medium temperature region $\left(620-1100^{\circ} \mathrm{C}\right)$, the weight of composites reduces rapidly, reaching the minimum at about $800-900^{\circ} \mathrm{C}$, and then rapidly increases. In this temperature region, the weight variation of composites is due to the weight loss from the oxidation of carbon fibers with coating and the $\mathrm{B}_{2} \mathrm{O}_{3}$ volatilization by the reactions (1) and (3), and the weight gain from the oxidation of amorphous/nanocrystalline matrix by chemical reactions (2) and (4). However, due to the high oxidation activation energy and the protective effect of the oxide film, oxidation rate of h-BN and $\mathrm{SiC}$ in the matrix is quite slower than that of the carbon component at relatively low temperatures, so at $620-900^{\circ} \mathrm{C}$, weight loss of carbon fibers is the dominant factor (see Fig. 11 (a-d)). However, above $1000{ }^{\circ} \mathrm{C}$, h-BN is rapidly oxidized and $\mathrm{SiC}$ begins to undergo obvious oxidation [20-22]. Therefore, with the temperature increasing from 900 to $1100^{\circ} \mathrm{C}$, the accelerated oxidation of $\mathrm{SiC}$ and h-BN leads to the weight gain (see Fig. $11(\mathbf{e}$ f)). Besides, with the outer carbon fibers consumed, a porous layer, containing amorphous/nanocrystalline matrix and its oxidation products is left outside, covering the unreacted core containing carbon component and the porous layer is gradually healed by molten oxidation product (see Fig. 12). Therefore, as temperature increases with oxidation time, the porous layer gradually becomes thicker and denser, causing more difficult internal diffusion of oxygen in the porous layer, so oxidation rate of carbon fibers decreases with oxidation time and temperature. The above factors lead to the obvious weight gain of composites at $900-1100^{\circ} \mathrm{C}$. Compared with $\mathrm{T} 1900\left(906^{\circ} \mathrm{C}\right)$ and $\mathrm{T} 2000\left(891^{\circ} \mathrm{C}\right)$ composites, weight of $\mathrm{T} 1800$ composite starts to increase at lower temperature $\left(860^{\circ} \mathrm{C}\right)$, with less weight loss $(17 \%)$ due to the looser matrix. The looser matrix favors oxygen diffusion and oxidation faster in the matrix, causing more weight gain. In addition, more oxidation products can more quickly heal porous layer and hinder the further oxidation of carbon fibers, causing less weight loss.

$$
\mathrm{C}(\mathrm{s})+\mathrm{O}_{2}(\mathrm{~g}) \rightarrow \mathrm{CO}_{2}(\mathrm{~g})
$$

1

$$
4 \mathrm{BN}(\mathrm{s})+3 \mathrm{O}_{2}(\mathrm{~g}) \rightarrow 2 \mathrm{~B}_{3} \mathrm{O}_{2}(\mathrm{l})+2 \mathrm{~N}_{2}(\mathrm{~g})
$$

$$
\mathrm{B}_{3} \mathrm{O}_{2}(\mathrm{l}) \rightarrow \mathrm{B}_{3} \mathrm{O}_{2}(\mathrm{~g})
$$




$$
\mathrm{SiC}(\mathrm{s})+2 \mathrm{O}_{2}(\mathrm{~g}) \rightarrow 2 \mathrm{SiO}_{2}(\mathrm{~s})+\mathrm{CO}_{2}(\mathrm{~g})
$$

4

In high temperature region $\left(1100-1400^{\circ} \mathrm{C}\right)$, the weight of the composites increases linearly at a lower rate. After rapid oxidation at $900-1100^{\circ} \mathrm{C}$, matrix is coated by oxide film, so oxidation rate of matrix is reduced significantly and more controlled by internal diffusion of oxygen in oxide film. Diffusion rate is less sensitive to temperature, so in this temperature region, weight increases linearly with temperature. Compared with T1900 and T2000 composites, T1800 composite still maintains a relatively higher weight gain rate, because its matrix is not dense with many micro-pores and is difficult to form a dense oxide film, aggravating oxidation weight gain of matrix.

Except for oxidation properties, coefficient of thermal expansion (TCE) is one of the important indicators that determine its thermal shock resistance. Fig. 9(b) shows the TCE of the $\mathrm{C}_{f} / \mathrm{SiBCN}$ composites perpendicular to hot pressing direction at different temperatures $\left(\mathrm{RT}-1200^{\circ} \mathrm{C}\right)$. The TCE of the T1800, T1900 and T2000 composites all increases with temperature $\left(0.43-1.6 \cdot 10^{-6} \mathrm{~K}^{-1}, 1.6-3.18 \cdot 10^{-6} \mathrm{~K}^{-1}, 1.33\right.$ $3.74 \cdot 10^{-6} \mathrm{~K}^{-1}$ ) and has the similar increasing trend. In lower temperature region (RT-600 ${ }^{\circ} \mathrm{C}$ ), the TCE increases rapidly, and in higher temperature region $\left(600-1200^{\circ} \mathrm{C}\right)$, the TCE increases slowly and tends to constant. The average TCE of the composites is smaller than that of SiC, SiC-BN and SiBCN monolithic, due to the limitation of fibers. Fibers are mainly distributed in horizontal plane and the axial TCE of fibers $\left(-0.14-1.7 \cdot 10^{-6} / \mathrm{K}\right)$ is much lower than matrix $\left(4-5 \cdot 10^{-6} / \mathrm{K}\right)$. During the heating process, TCE mismatch of matrix and fibers in the horizontal plane causes compressive stress in matrix to limits the thermal expansion of the matrix. With increasing sintering temperature, the thermal expansion coefficient of the composites increases: the TCE of T1900 and T2000 composites is close to that of C/SiC composites, while the TCE of T1800 composite is much lower, due to more amorphous phase and micro-pore in the matrix. Many atom gaps in amorphous phase, due to the disorder arrangement of atoms, provide space for the thermal vibration of atoms, and more micro-pores, due to lower relative density, provide space for the thermal expansion of grains, resulting in a lower thermal expansion coefficient.

\subsection{Effect of sintering temperature on thermal shock properties of composites}

The thermal shock resistance of the composites is characterized by residual bending strength after thermal shock. Fig. 10 shows the residual bending strength of the composites after thermal shock at different temperatures $\left(700-1100^{\circ} \mathrm{C}\right)$. After thermal shock at $700{ }^{\circ} \mathrm{C}$, the bending strength of $\mathrm{T} 1900$ and T2000 composites is reduced by $40.9 \%$ and $43.1 \%$, respectively. For T1900 and T2000 composites, due to stronger interface bonding, the thermal stress at the interface is hard to be alleviated by fiber debonding and the tensile stress in the matrix is more likely to accumulate to the yield strength of the matrix causing more cracks in the matrix and decrease of mechanical properties. In addition, at $700^{\circ} \mathrm{C}$ although fibers are less damaged (see Fig. 11(a)), resin-derived carbon coating as interfacial phase is damaged seriously 
due to oxidation and thermal stress, so the interface with weakened bonding strength cannot effectively transfer the load to fibers (see Fig. 11(b)), resulting in a significant decline in mechanical properties. However, after thermal shock at $700{ }^{\circ} \mathrm{C}$, the strength of T1800 reduces by only $20.4 \%$. For one thing, due to the lower CET, the internal stress caused by thermal shock is less and due to the weak interface bonding, the thermal stress at the interface can be alleviated by fiber debonding, causing less damage to matrix. For another, due to the weak interface bonding, interface in T1800 composite originally cannot transfer the load to fibers effectively, so after thermal shock, the further damage on interface has less effect on mechanical properties.

With further increasing thermal shock temperature $\left(T=900^{\circ} \mathrm{C}, 1100^{\circ} \mathrm{C}\right)$, the strength of the composites decreases further, but the decrease is limited. Although the oxidation of carbon fibers is significantly intensified (see Fig. 11(c-f)), its effect on mechanical properties is less because strength of the composites is more determined by interface bonding strength rather than fiber strength. After the thermal shock at $1100^{\circ} \mathrm{C}$, the color of the composite surface turns white. Based on the EDS analysis (Table 1) and SEM observation, the white material is oxidation products $\left(\mathrm{SiO}_{2}\right)$, which heals pores, cracks, inhibiting further decrease of composite strength. In summary, due to the lower coefficient of thermal expansion, lower fiber loading ratio, less stress concentration at the interface, and better defect healing effect, T1800 composite has the best thermal shock resistance, which is consistent with the analysis of the oxidation and thermal expansion properties of the composites.

Figure 11 shows the surface and fracture morphology of T2000 composite after thermal shock at different temperatures. As shown in Figure $11(a-b)$, after thermal shock at $700^{\circ} \mathrm{C}$, there is no obvious oxidation of the matrix. Carbon fibers are only slightly oxidized: the active points of the carbon fibers are oxidized to form pits. However, obvious oxidation of the resin-derived carbon interface forms obvious gaps between fibers and matrix, causing the failure of the fibers to load through the interface, and significant decrease in the mechanical properties, as is analyzed above. Compared with the fracture morphology before thermal shock (see Fig. 8(d)), the fiber pull-out length increases considerably, due to the failure of the interface.

Figure 11 (c-d) shows the surface morphology and fracture morphology of T2000 composites after thermal shock at $900^{\circ} \mathrm{C}$. The carbon fibers on surface are oxidized seriously to shape of bamboo shoots and even are completely consumed to leave many holes as channel of oxygen internal diffusion. At the fracture surface, the carbon fibers near the surface are completely consumed, and the carbon fibers away from the surface are not oxidized obviously due to the excessive oxygen diffusion resistance. Figure 11 (ef) shows surface morphology and fracture morphology of T2000 composite after thermal shock at $1100^{\circ} \mathrm{C}$. The carbon fibers on surface are completely consumed to leave holes. According to EDS analysis results, the matrix is obviously oxidized to form molten $\mathrm{SiO}_{2}$ (see in Table 1 ) that tends to cover the surface and heal pores and cracks. According to the fracture morphology, deeper carbon fibers are also obviously oxidized, indicating that the oxygen diffusion depth further increases. 
Figure 12 (a-d) shows enlarged view of the fracture morphology from the surface to the inside successively, and obviously the oxidation degree gradually decreases with depth. The fibers of the composite near the surface are almost completely oxidized, leaving large holes in the matrix and the

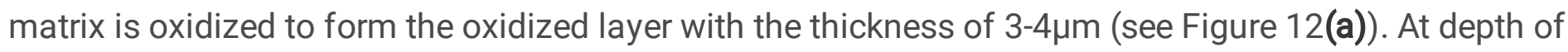
around $100 \mu \mathrm{m}$, fibers are oxidized seriously, with bamboo-shoot shape and the fiber surface is covered by molten oxide that plays a protective role of coating (see Figure 12(b)). Based on the EDS analysis, the main component of the molten oxide is $\mathrm{SiO}_{2}$ (see Table 1). Similarly, the spherical molten oxide melt is also formed on the surface of hole left by fiber oxidation, indicating that the oxidation product can heal pores and cracks, hindering oxygen diffusion and further oxidation of composites. At depth of about $200 \mu \mathrm{m}$, fiber front becomes significantly thinner, the interface phase is completely oxidized, and there is clear gap between fibers and matrix (see Figure 12(c)). Due to weak bonding or even complete debonding of fibers and matrix, the fiber pull-out length is significantly greater than that before the thermal shock. However, at depth of $300 \mu \mathrm{m}$, the fibers still maintain their initial morphology and have good bonding with the matrix (see Figure 12(d)). The fiber pull-out length is close to that before the thermal shock, indicating that the degradation of interface bonding strength is less.

Table 1

Element analysis result at different spot

by EDS

\begin{tabular}{|llll|}
\hline \multirow{2}{*}{ EDS } & \multicolumn{3}{l|}{ Atomic content of element \% } \\
\cline { 2 - 4 } & Si K & C K & O K \\
\hline Spot 1 & 0 & 100 & 0 \\
\hline Spot2 & 31.53 & 0 & 78.47 \\
\hline Spot3 & 37.21 & 0 & 62.79 \\
\hline
\end{tabular}

In summary, damage to the interface makes fibers fail to carry load effectively causing the decrease in the strength of T2000 composite. Due to the high activity of the resin-derived carbon, the strength of the composite is significantly degraded after thermal shock at a lower temperature $\left(700^{\circ} \mathrm{C}\right)$. With the temperature difference further increasing, although carbon fibers are more severely oxidized, further degradation of strength is relatively less, due to the damaged interface and the self-healing effect of oxidation product.

\section{Conclusion}

In this study, after preparations of resin derived carbon fiber coating by polymer impregnation pyrolysis method (PIP) and amorphous SiBCN powder by mechanical alloying (MA), three kinds of $\mathrm{C}_{f} / \mathrm{SiBCN}$ composites (T1800, T1900, and T2000) were prepared by hot pressing at different sintering temperatures $\left(1800^{\circ} \mathrm{C}, 1900^{\circ} \mathrm{C}\right.$ and $\left.2000^{\circ} \mathrm{C}\right)$. The effects of sintering temperature $\left(1800-2000^{\circ} \mathrm{C}\right)$ on microstructure, 
mechanical properties, thermal shock resistance, and failure mechanisms of the $\mathrm{C}_{\mathrm{f}} / \mathrm{SiBCN}$ composites were studied. The main results are as follows:

(1) During the pyrolysis process, the weight loss of phenolic resin mainly occurs at $300-600^{\circ} \mathrm{C}$, the weight loss at $350-400{ }^{\circ} \mathrm{C}$ is the fastest corresponding to decomposition of main chain, and carbon residue rate is about $38.8 \%$. After pyrolysis, resin-derived carbon coating cover the longitudinal grooves and well bond to carbon fibers, with less coating peeling and shedding. During sintering, SiBCN matrix of the composites is obviously crystallized, precipitating $\mathrm{BN}(\mathrm{C}), \mathrm{a}-\mathrm{SiC}$, and $\beta$-SiC phase, and the crystallinity increases with increasing sintering temperature.

(2) Because fiber bridging hinders the flow and rearrangement of particles and increases the diffusion distance, the addition of fiber hinders the sintering densification, causing more defects in the fiber-dense area and lower strength. However, through fiber debonding, fracture, pull-out, all composites are not sensitive to the defects and present pseudoplastic behavior.

(3) Higher sintering temperature can significantly improve comprehensive mechanical properties of the composites, including bending strength (30.4-70.5MPa), vickers hardness (0.91-2.25 GPa) and elastic module (20.3-41.6 GPa), because further sintering densification enhances matrix strength and fiber/matrix interface bonding strength. However, fracture toughness is less influenced by sintering temperature (2.24-2.38 MPa $\left.\mathrm{m}^{1 / 2}\right)$, due to counteraction of debonding resistance and pull-out length. However, fiber coating can improve fracture toughness significantly via protecting carbon fibers from chemical corrosion and damage of thermal stress and external stress.

(4) According to the thermogravimetric curves of non-isothermal oxidation, the oxidation process of composites can be divided into three stages: In the low-temperature section (RT-620 ${ }^{\circ} \mathrm{C}$ ), there is an obvious weight loss $(5 \%)$ at $180-260^{\circ} \mathrm{C}$ due to the water volatilization and gas desorption. In the mediumtemperature region $\left(620-1100^{\circ} \mathrm{C}\right)$, due to the different chemical activity, the dominant factor to weight change transfers from carbon fiber consumption $\left(620-900^{\circ} \mathrm{C}\right)$ to matrix oxidation $\left(900-1100^{\circ} \mathrm{C}\right)$. In the high-temperature region $\left(1100-1400^{\circ} \mathrm{C}\right)$, the oxidation rate of matrix is more controlled by the internal diffusion of oxygen in the oxide film resulting that weight increases linearly at a lower rate. Thermal expansion coefficients (TCE) of T1800, T1900, and T2000 composites all increase with temperature $\left(0.43-1.6 \cdot 10^{-6} \mathrm{~K}^{-1}, 1.6-3.18 \cdot 10^{-6} \mathrm{~K}^{-1}, 1.33-3.74 \cdot 10^{-6} \mathrm{~K}^{-1}\right)$ and the TCE of T1800 composite is significantly lower, due to more amorphous phase and micro-pore in the matrix.

(5) Due to the lower coefficient of thermal expansion, lower fiber loading ratio, less stress concentration at the fiber/matrix interface, and better defect healing effect, T1800 composite has the best thermal shock resistance. Thermal shock recession mechanisms of T1900 and T2000 composites are the damage of interface.

\section{Declarations}




\section{Acknowledgements}

This work was financially supported by the National Natural Science Foundation of China (Grant no. 52002092, 51832002, 52172068), Heilong Jiang Natural Science Fund for Young Scholars (Grant no. YQ2021E017), National Key Research and Development Program of China (Grant no. 2017YFB0310400) and Heilongjiang Touyan Team Program.

\section{References}

1. M Zhang, Q. Chen, Y. Peng. A comparative study on high temperature oxidation behavior of SiC, SiCBN and SiBCN monoliths, Corros Sci, 192 (13) (2021) pp: 109855. https://doi.org/10.1016/j.corsci.2021.109855

2. B. Liang, Q. Zhu, X. Liao, et al. Crystallinity dependence of high-temperature oxidation of silicoboron carbonitride monoliths, Corros Sci, 187 (2021) pp: 109473. https://doi.org/10.1016/j.corsci.2021.109473

3. G. Zhang, J. Yang, T. Ohji, et al. In situ $\mathrm{Si}_{3} \mathrm{~N}_{4}-\mathrm{SiC}-\mathrm{BN}$ composites: preparation, microstructures and properties, Mat Sci Eng A-Struct, 328 (1-2) (2002) pp: 201-205 https://doi.org/10.1016/S09215093(01)01677-X

4. M. Weinmann, J. Schuhmacher, H. Kummer, et al. Synthesis and Thermal Behavior of Novel SiBCN Ceramic Precursors, Chem. Mater, 12 (3) (2000) pp: 623-632. https://doi.org/10.1021/cm9910299

5. G. Ervin. Oxidation Behavior of Silicon Carbide, J Am Ceram Soc, 41 (9) (2006) pp: 347 - 352. DOI: 10.1111/j.1151-2916.1958.tb12932.x

6. M. Opeka, I. Talmy, J. Zaykoski. Oxidation-based materials selection for $2000^{\circ} \mathrm{C}+$ hypersonic aerosurfaces: Theoretical considerations and historical experience, J Mater Sci, 39 (19) (2004) pp: 5887-5904.

DOI: 10.1023/B:JMSC.0000041686.21788.77

7. D. Jia, B. Liang, Z. Yang, et al. Metastable Si-B-C-N ceramics and their matrix composites developed by inorganic route based on mechanical alloying: Fabrication, microstructures, properties and their relevant basic scientific issues, Prog Mater Sci, 98 (2018) pp: 1-67.

https://doi.org/10.1016/j.pmatsci.2018.05.006

8. D. Li, D. Jia, Z. Yang, et al. Principles, design, structure and properties of ceramics for microwave absorption or transmission at high-temperatures, Int Mater Rev, 6 (2021) pp: 1-32.

https://doi.org/10.1080/09506608.2021.1941716

9. R. Riedel, A. Kienzle, W. Dressler, et al. A silicoboron carbonitride ceramic stable to $2000^{\circ} \mathrm{C}$, Nature 382 (6594) (1996) pp: 796-798.

DOI: $10.1038 / 382796 a 0$

10. B. Wang, D. Li, Z. Yang, et al. Microstructural evolution and mechanical properties of in situ nano $\mathrm{Ta}_{4} \mathrm{HfC}_{5}$ reinforced SiBCN composite ceramics, J Adv Ceram, 9 (6) (2020) pp: 739-748. DOI: 
11. Q. Zhu, X. Liao, D. Ao, et al. Enhanced ablation resistance of $\mathrm{HfB}_{2}-\mathrm{HfC} / \mathrm{SiBCN}$ ceramics under an oxyacetylene torch environment, Corros Sci, 187 (2021) pp:

109509. https://doi.org/10.1016/j.corsci.2021.109509

12. Q. Ding, B. Chen, $\mathrm{D}$. Ni, et al. Improved ablation resistance of $3 D-C_{f} / S i B C N$ composites with (PyC/SiC) ${ }_{3}$ multi-layers as interphase, J Eur Ceram Soc, 41 (2) (2020) pp: 1114-

1120 https://doi.org/10.1016/j.jeurceramsoc.2020.09.025

13. B. Feng, Z. Wang, Y. Fan, et al. Creep deformation behavior during densification of $\mathrm{ZrB}_{2}-\mathrm{SiBCN}$ ceramics with $\mathrm{ZrO}_{2}$ additive, J Adv Ceram, 9 (2020) pp: 544-557. DOI: 10.1007/s40145-020-0393-6

14. D. Li, Z. Yang, D. Jia, et al. Microstructure, oxidation and thermal shock resistance of graphene reinforced SiBCN ceramics. Ceram Int, 42 (3) (2016) pp: 4429-4444.

https://doi.org/10.1016/j.ceramint.2015.11.127

15. J. Han, D. Su, Z. Zhao, et al. Fabrication and toughening behavior of carbon nanotube (CNT) scaffold reinforced SiBCN ceramic composites with high CNT loading, Ceram Int, 43 (12) (2017) pp: 90249031.

https://doi.org/10.1111/jace.16202

16. B. Chen, Q. Ding, D. Ni, et al. Microstructure and mechanical properties of 3D $C_{f} / S i B C N$ composites fabricated by polymer infiltration and pyrolysis, J Adv Ceram, (2020) https:// doi.org/10.21203/rs.3.rs-32542/v1

17. D. Li, Z. Yang, Jia D, et al. Dense amorphous $\mathrm{Si}_{2} \mathrm{BC}_{1-4} \mathrm{~N}$ monoliths resistant to high-temperature oxidation for hypersonic vehicle, Corros Sci, 163 (2020) pp:

108231. https://doi.org/10.1016/j.corsci.2019.108231

18. F. Huang, S. Jiao. Phenolic resins and its application Chemical Industry Press, Beijing, 2003.

19. Z. Yang, D. Chang, Y. Zhou. Silicon-boron-carbon-nitrogen system metastable ceramics and its composite materials prepared by inorganic method, Science Press, Beijing, 2019.

20. S. Fan, L. He, C. Yang, et al. Effect of $\mathbf{B}_{4} \mathbf{C}$ on the microstructure and properties of $\mathbf{B}_{4} \mathbf{C}$ modified threedimensional needled C/C-SiC composites, Mat Sci Eng A-Struct, 706 (26) (2017) pp: 201-210. https://doi.org/10.1016/j.msea.2017.09.008

21. R. Naslain, A. Guette, F. Rebillat, et al. Oxidation mechanisms and kinetics of SiC-matrix composites and their constituents, J Mater Sci, 39 (24) (2004) pp: 7303-7316. DOI:

10.1023/b:jmsc.0000048745.18938.d5

22. V.A. Lavrenko, A.F. Alexeev. High-temperature oxidation of boron nitride, Ceram Int, 12 (1) (1986) pp: 25-31. DOI: 10.1016/s0272-8842(86)80006-2

\section{Figures}




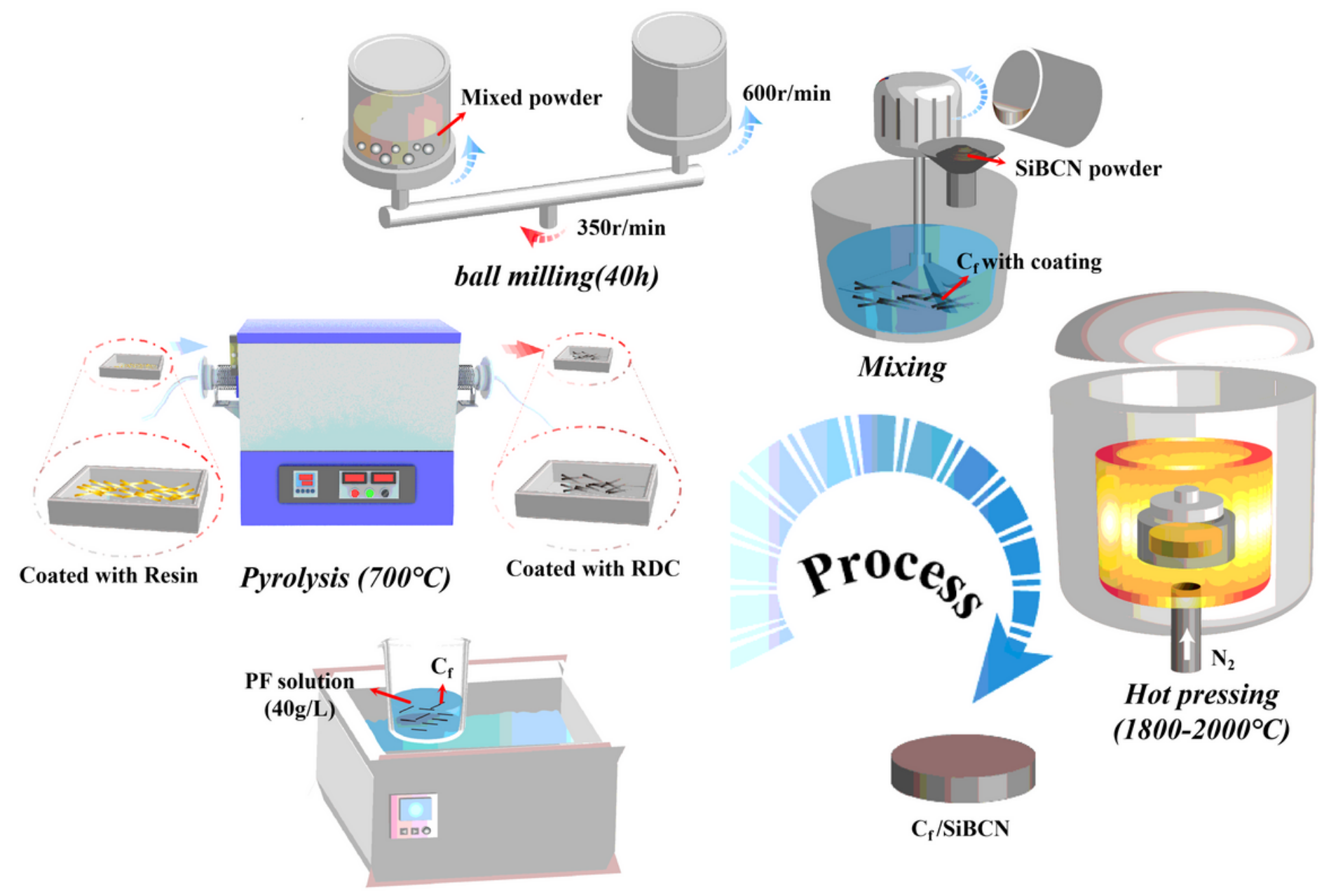

Immersion/Ultrasonic dispersion

Figure 1

Schematic diagram of preparation process of $\mathrm{Cf} / \mathrm{SiBCN}$ composite
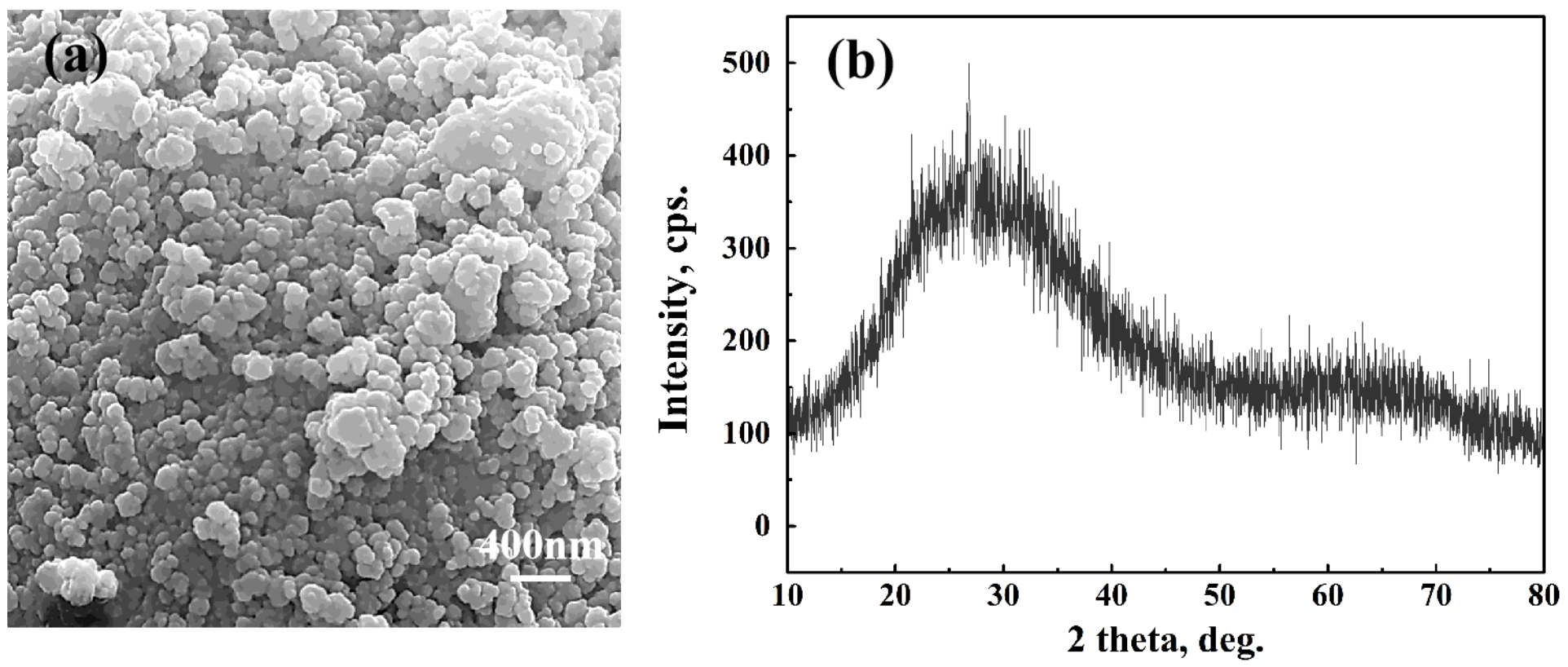
Figure 2

(a-b) Microstructure and XRD pattern of amorphous SiBCN powder

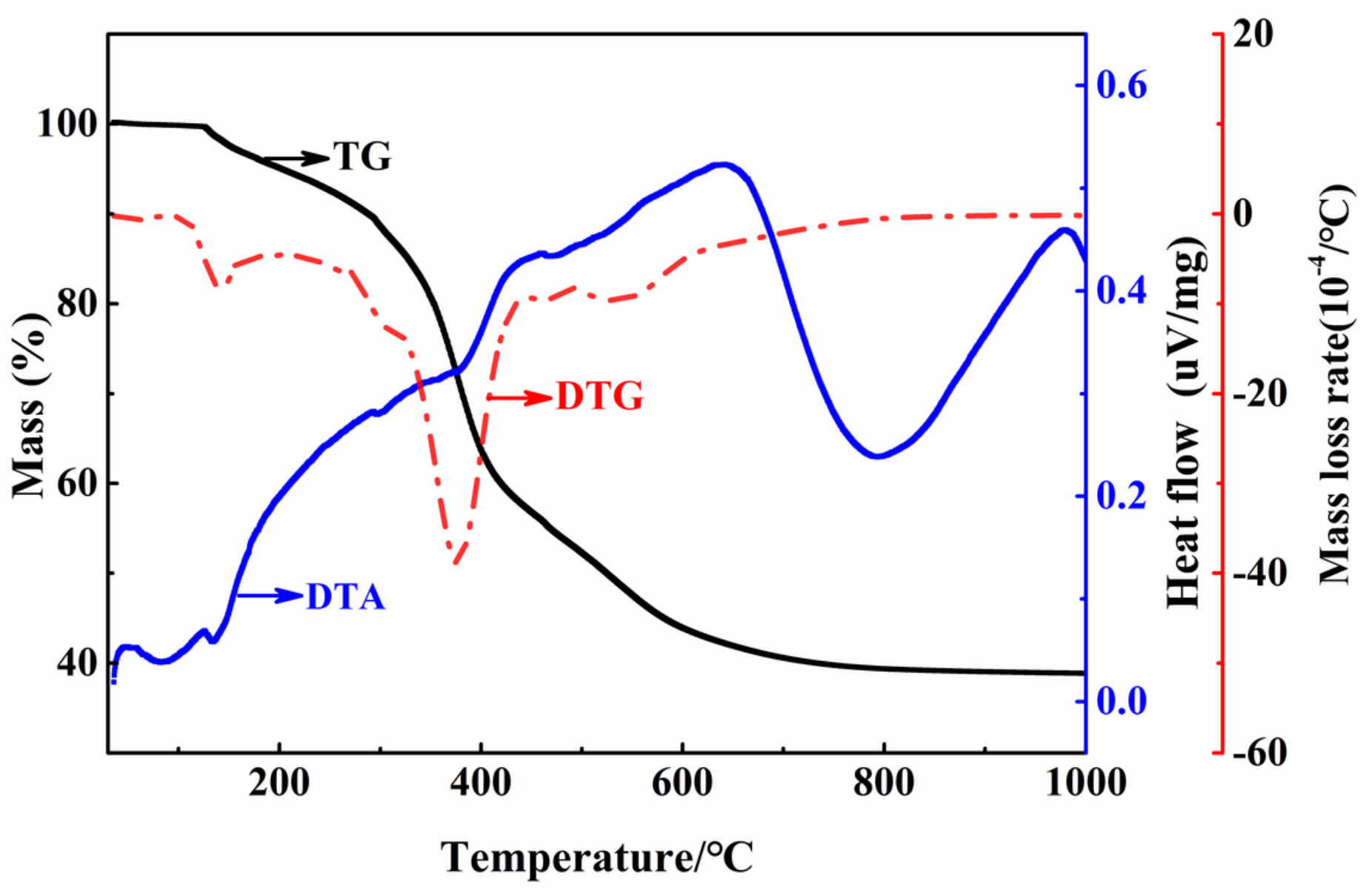

Figure 3

TG, DTG and DTA curves of phenolic resin 

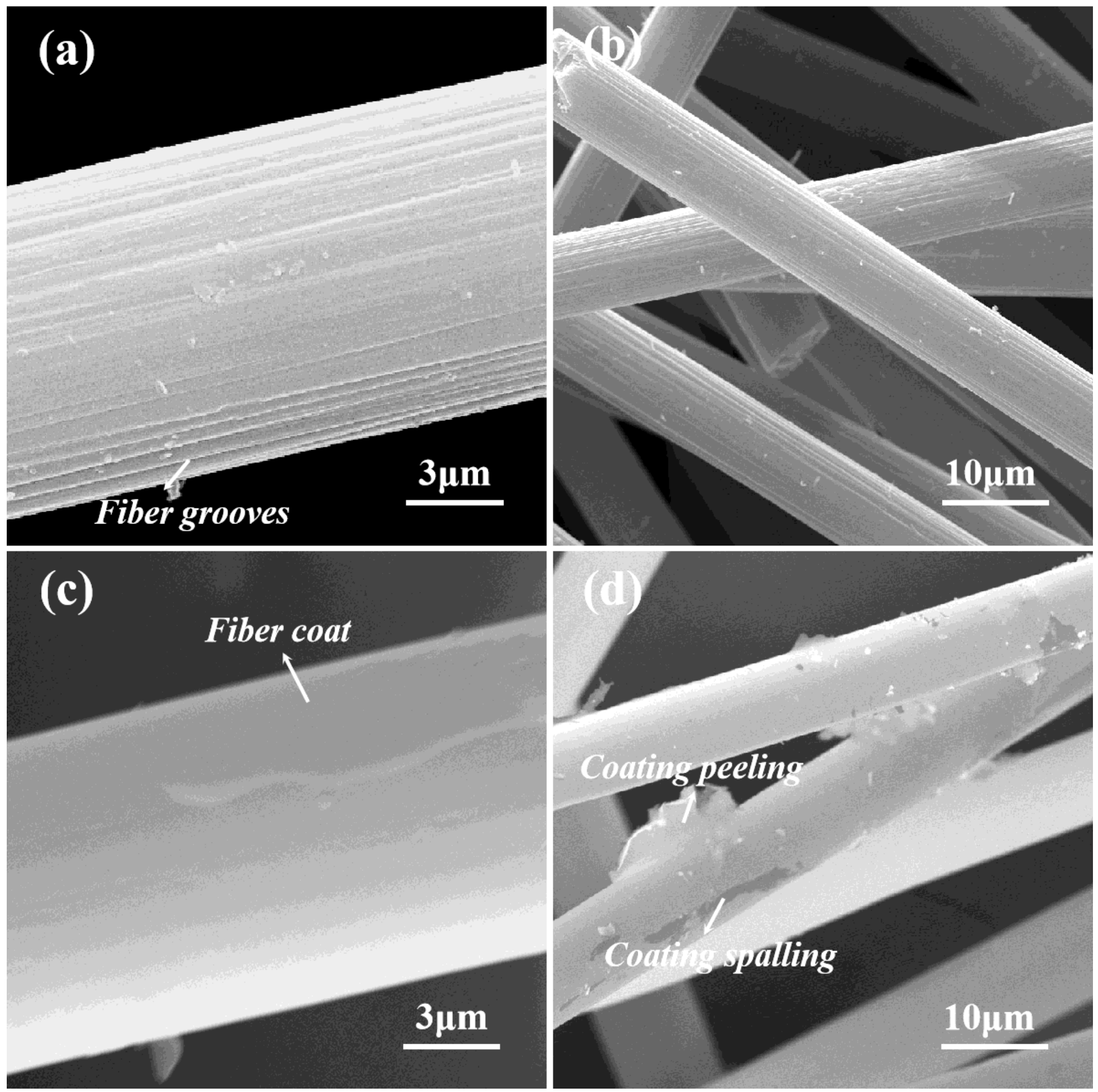

Figure 4

(a-b) microstructure of degummed carbon fibers; (c-d) microstructure of carbon fibers with the resinderived carbon coating

原

Figure 5 
(a-c) surface morphology of T1800, T1900, T2000 composites; (d) XRD pattern of the different Cf/SiBCN composite
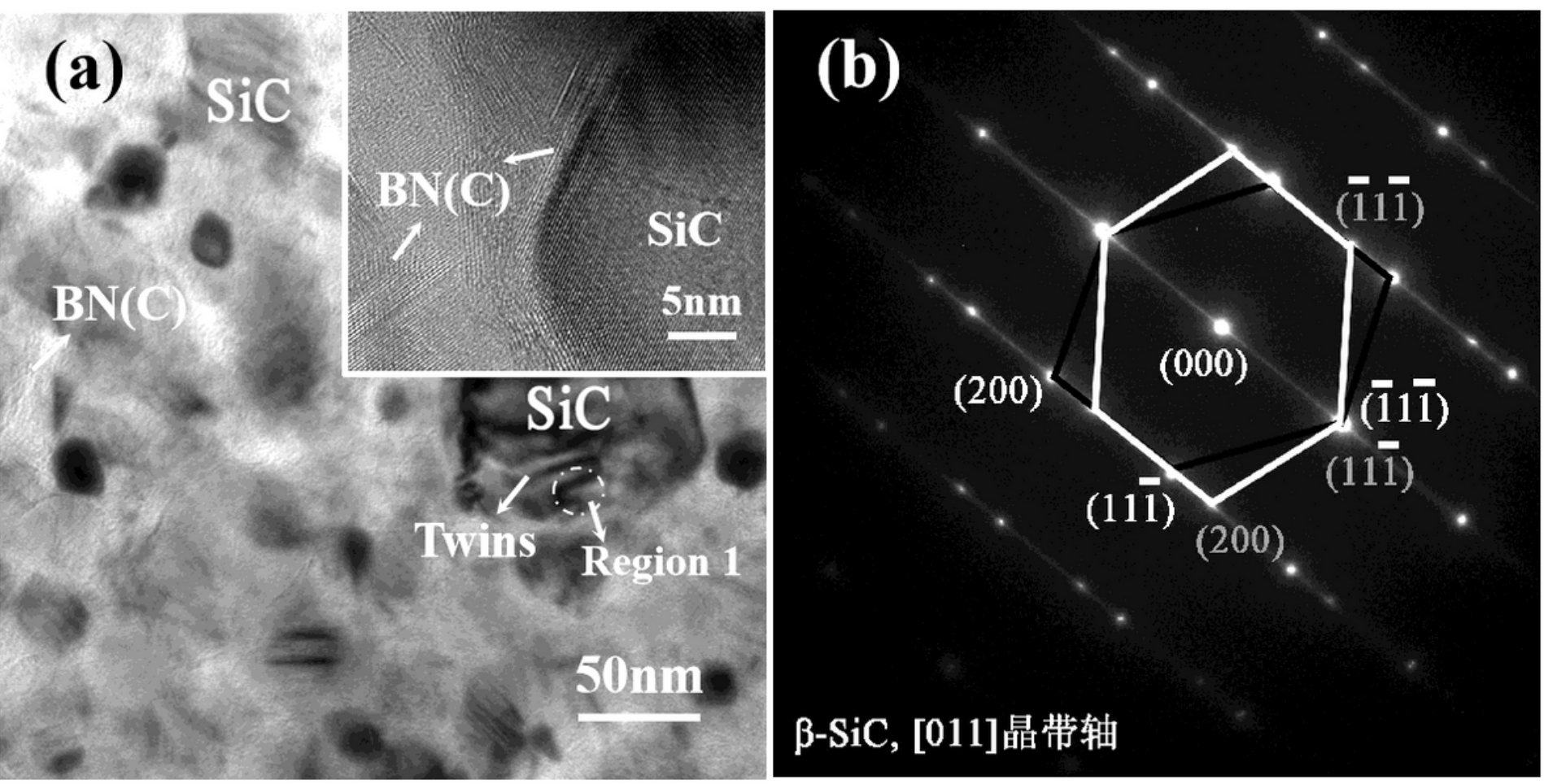

Figure 6

(a) microscopic structure in matrix of T1900 composites; (b) electron diffraction pattern of the region 1

(a)

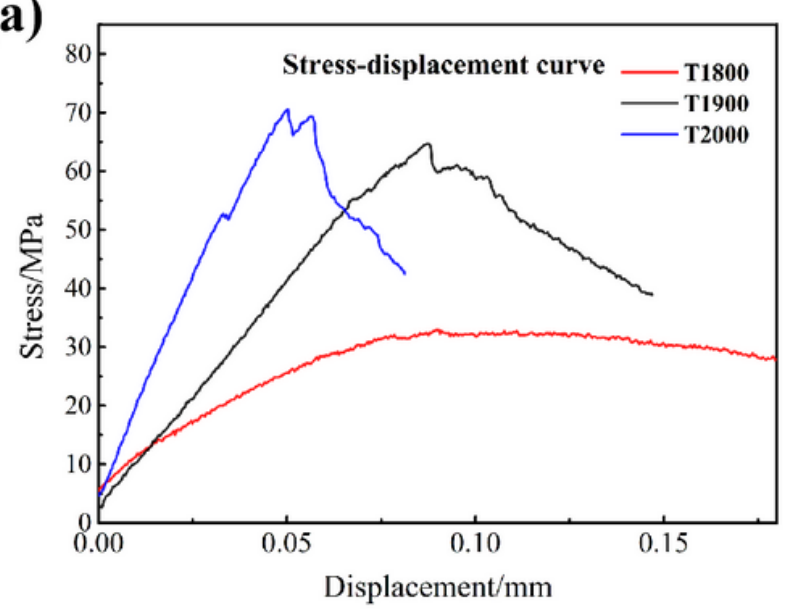

(b)

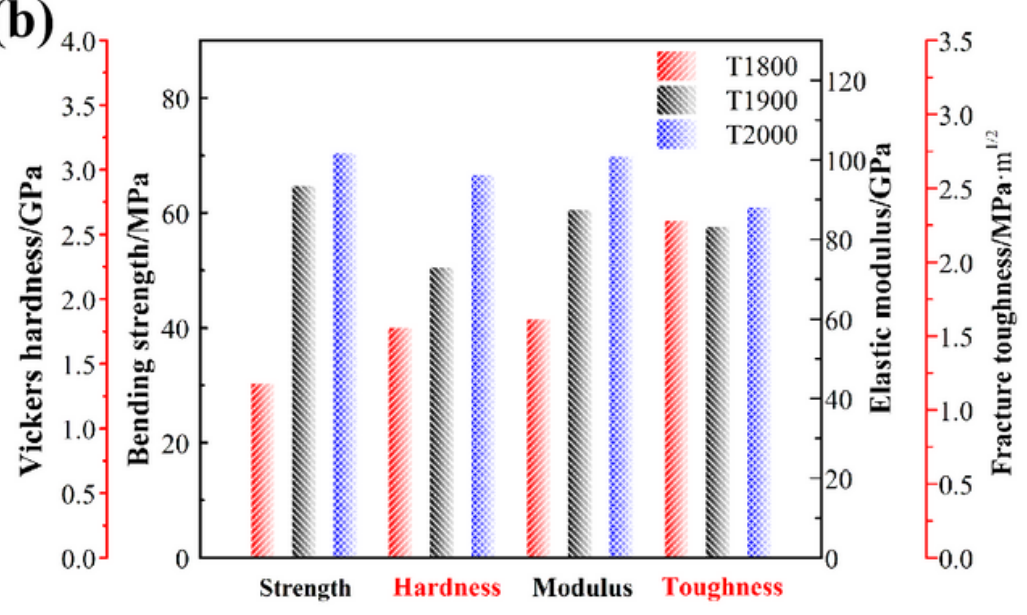

\section{Figure 7}

(a) bending stress-displacement curve of the different composites; (b) comprehensive mechanical properties of the different composites

原

Figure 8 
(a) fracture morphology of $\mathrm{Cf} / \mathrm{SiBCN}$ composite without fiber coating with the same sintering process as that of T1800 composites; (b-d) fracture morphology of T1800, T1900, T2000 composites respectively
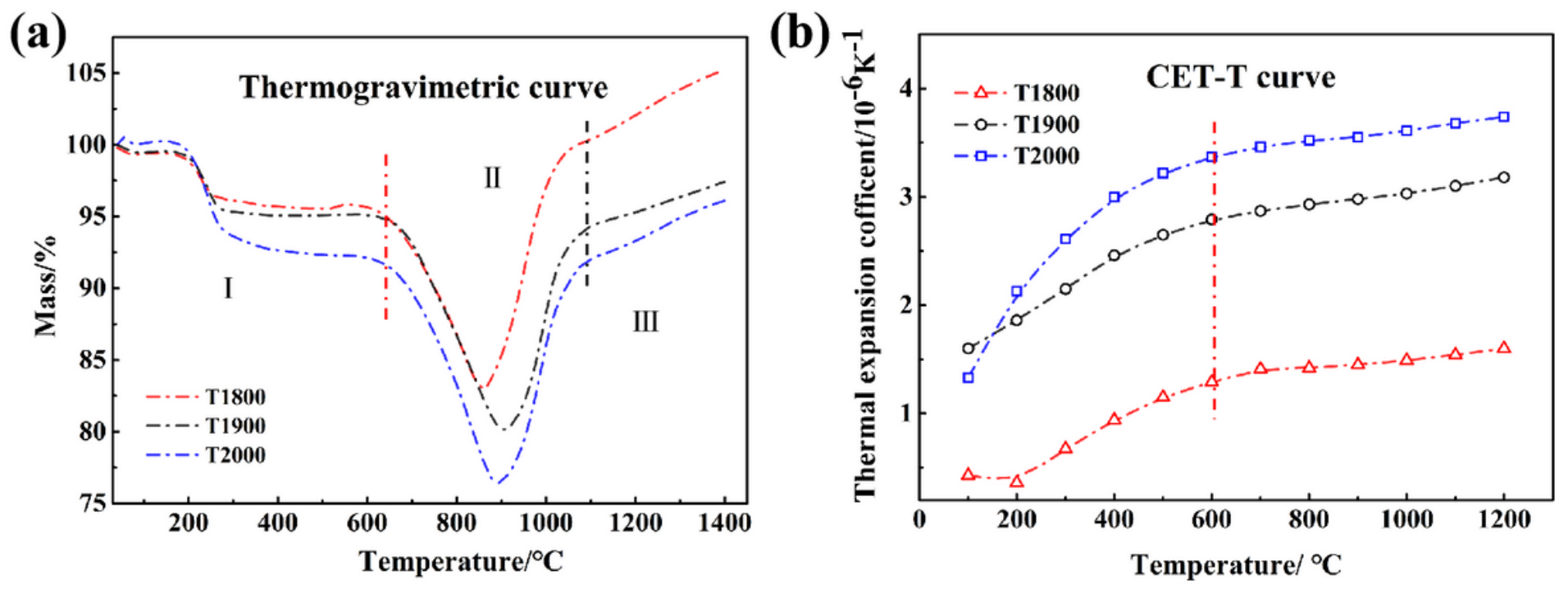

Figure 9

(a) Weight loss curve of non-isothermal oxidation of the different composites; (b) Curve of Coefficient of Thermal Expansion with Temperature of the different composites

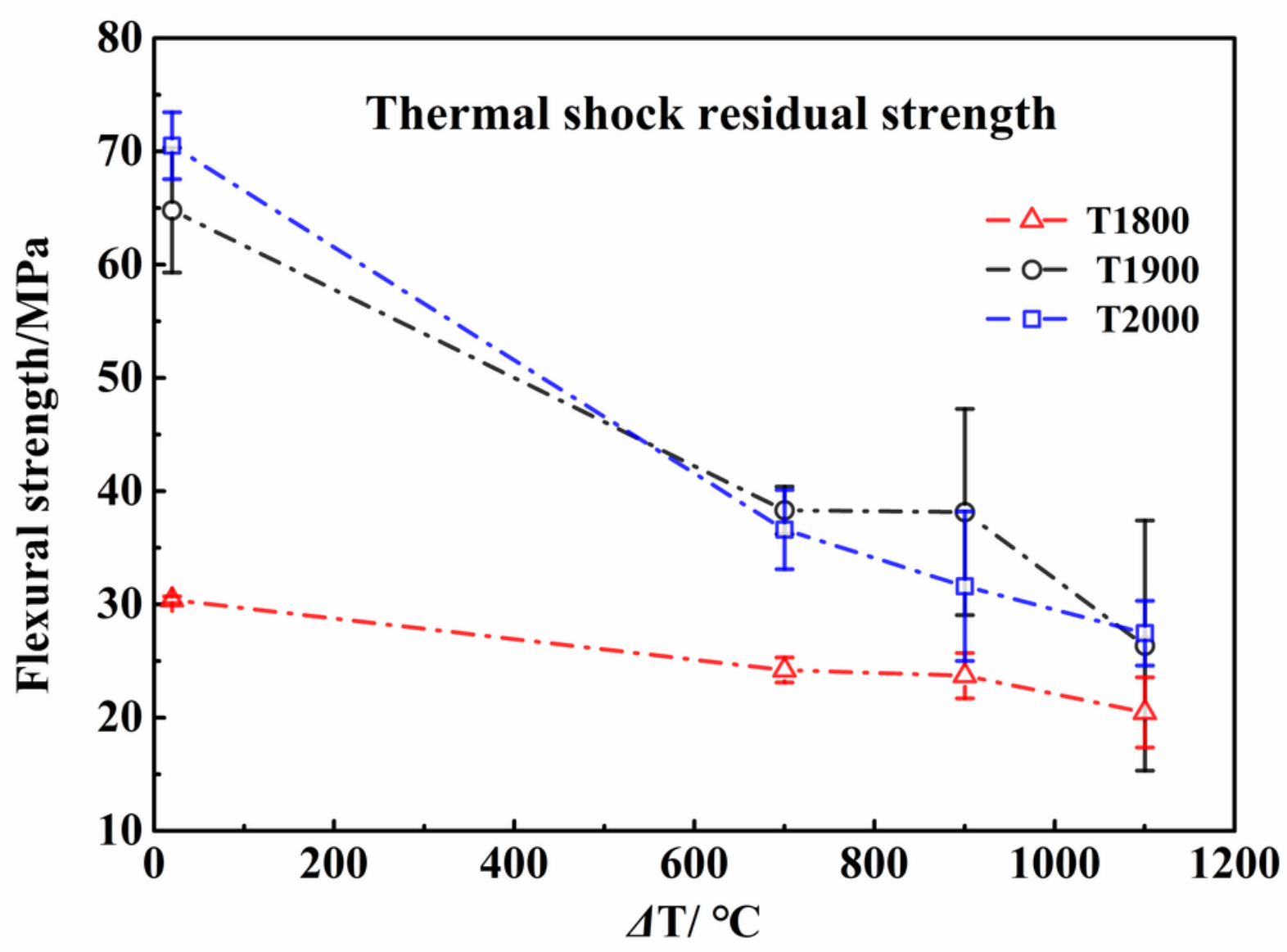




\section{Figure 10}

Residual strength of the different composite after different $\Delta T$ thermal shocks
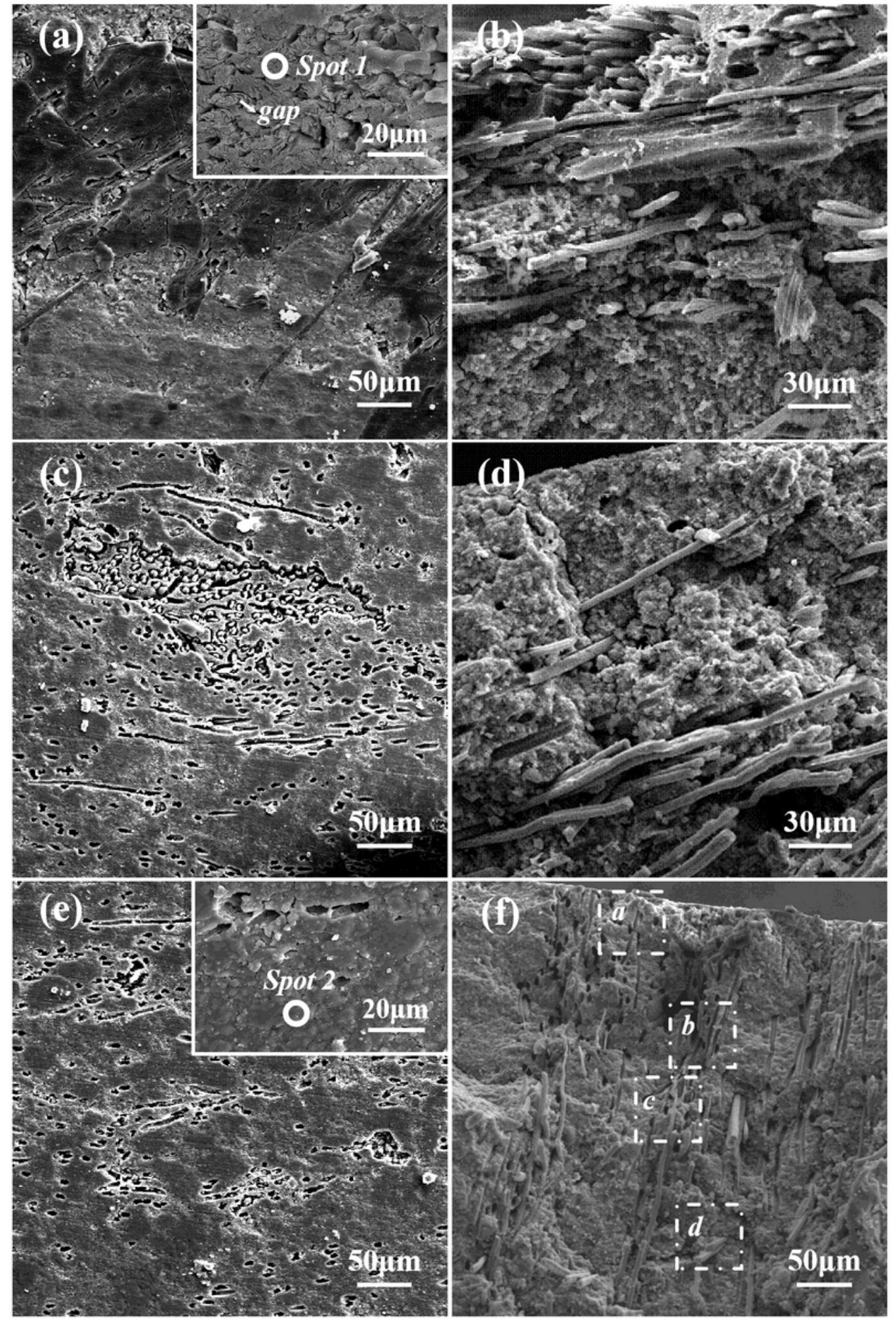

\section{Figure 11}

Surface and fracture morphology of T2000 composites after thermal shock at different temperatures: (a-

b) $700^{\circ} \mathrm{C}$; (c-d) $900^{\circ} \mathrm{C}$; (e-f) $1100^{\circ} \mathrm{C}$ 


\section{Figure 12}

(a-d): Amplifications of a-d regions in Fig. 11(d), respectively 